\title{
Apertura dos centros de formación profesional á contorna local: percepción dos axentes sociais
}

\section{Opening of the vocational training schools to the local context: perception of the social agents involved}

\author{
Laura Rego*, Eva M. Barreira**, Raquel Mariño** \\ *Dpto. Pedagoxía e Didáctica, Universidade da Coruña, \\ ** Dpto. Didáctica e Organización Escolar, Universidade de Santiago de Compostela
}

\begin{abstract}
Resumen
Tomando como referente o modelo de Desenvolvemento Humano e Sustentable formúlase un estudo descritivo centrado na contribución que poden realizar as ensinanzas de formación profesional do sistema educativo a este modelo na contorna comarcal. Foi posible aplicar a técnica de triangulación de fontes, instrumentos e datos baixo unha metodoloxía mixta para coñecer como os centros de FP do territorio analizado se relacionan coa súa contorna e como é posible incrementar o capital social xerado arredor das escolas profesionais. Preséntanse así, os resultados relativos á percepción dos distintos axentes sociais enquisados —alumnado de FP; profesorado; empresas e titulados/as- dunha comarca galega.
\end{abstract}

Palabras clave: formación profesional, centros de formación profesional, relación escola e empresa; capital social, recursos da comunidade.

\begin{abstract}
Drawing on the model of sustainable human development, it has been formulated a descriptive study focused on the contribution that can be made the vocational education system in the local environment to achieve this kind of development. It was applied the technique of triangulation of sources, instruments and data under a mixed methodology and in order to know how the vocational training schools collaborate with their social context and how it is possible to increase the social capital generated around the vocational training. The main results are related to the perception of different social agents - trainees, trainers, companies and graduates- in a county in Galicia (Spain).
\end{abstract}

Keywords: vocational education, vocational training centers, school business relationship, social capital, community resources.

\section{Introdución}

A vivencia nun mundo cada vez máis interconectado, lévanos a reformular a concepción do desenvolvemento e tamén o rol que xogan a Formación Profesional (de aqui en diante, FP) á hora de acadar ese obxectivo social común.
Preténdese así, realizar unha valoración das conexións existentes entre os distintos axentes sociais que participan da FP inicial na comarca do Barbanza (A Coruña) en relación coa apertura dos centros educativos á contorna como clave dunha FP inicial integradora e facilitadora da inserción sociolaboral do alumnado. Neste senso, baseámonos na teoría do capital social, especialmente nas propostas de Fukuyama (2003) ou Atria (2003), ambos centrados en analizar en que medida este é indispensable para a promoción do desenvolvemento das comunidades.

\section{Método}

A continuación presentaremos os resultados parciais dunha investigación de tese de doutoramento cuxo método de indagación é, tomando como criterio a manipulación das variables, de carácter descritivo. Deste xeito, o estudo combina a metodoloxía cualitativa coa cuantitativa, polo que se desenvolve un proceso mixto de obtención e análise dos datos. Nos epígrafes seguintes describiremos o proceso metodolóxico seguido, centrándonos nos obxectivos e a metodoloxía; os instrumentos utilizados para a recompilación dos datos e os distintos tipos de poboación e mostra a partir dos cales se obtivo a información.

\section{Obxectivos e metodoloxía}

Este estudo foi construído tomando en consideración unha metodoloxía descritiva mixta -cualitativa e cuantitativa-, na que o obxectivo xeral da investigación foi coñecer a perspectiva dos axentes sociais —alumnado de FP; titulados; empresarios e profesorado destes estudos - acerca da relación entre a FP inicial e o desenvolvemento humano e sustentable nun territorio comarcal concreto de Galicia, neste caso, a comarca do Barbanza, localizada ao sur da provincia da Coruña (Rego Agraso, 2013). Do mesmo xeito, buscouse coñecer a perspectiva e os modelos de actuación da Administración Educativa autonómica respecto da vinculación entre a FP inicial e o desenvolvemento humano sustentable. E finalmente, con todo iso, tratouse de analizar as perspectivas de tódolos axentes enquisados de forma comparada, contrastando a información obtida cun estudo previo do mercado laboral e a oferta formativa do territorio. 
Entre as variables obxecto de estudo atópase a relación que manteñen os centros de FP e as propias empresas con distintas organizacións da súa contorna, así como a frecuencia dos contactos no tempo.

En canto ao proceso seguido para a obtención e análise dos datos, partimos da formulación esquemática do problema para determinar as fontes e a información necesaria para a resolución do mesmo e tamén os instrumentos empregados para tal fin. Unha vez establecido isto, procedeuse á fase de recollida de información e a súa análise posterior, no que confrontamos cada unha das perspectivas recompiladas para dar lugar ás conclusións do estudo.

Construíronse así, catro cuestionarios diferenciados en función de cada un da informantes clave, en cuxos resultados respecto da relación que se mantén coas organizacións da contorna, centrarémonos no epígrafe seguinte. Os devanditos instrumentos foron aplicados no ano académico 2011-2012. De igual modo, obtívose a modo de contraste e en aras de alcanzar unha triangulación real de métodos, instrumentos e datos, a perspectiva do Director Xeral de FP da Xunta de Galicia como representante da Administración Educativa Autonómica, empregando para iso, unha entrevista semiestruturada. Por último, de forma complementaria, realizouse unha análise do mercado laboral da comarca obxecto de estudo en contraposición á oferta formativa existente - ciclos de FP-, obtendo a información do que se denomina fontes secundarias e dos directores dos centros implicados mediante a realización dunha entrevista con cada un deles.

\section{Poboación e mostra}

No estudo que aquí se presenta (Rego Agraso, 2013) empregouse en tódolos casos —alumnado, titulados/as, persoal docente e empresarios/as - unha mostraxe aleatoria probabilística estratificada; no caso dos empresarios/as en función do municipio no que desenvolven a súa actividade, e no caso dos demais colectivos, en función do centro educativo co que manteñen ou mantiveron vinculación. Na táboa que se presenta a continuación é posible apreciar a poboación e a mostra en cada caso, así como o nivel de confianza alcanzado e a marxe de erro.

Táboa 1.

Poboación, ,mostra, nivel de confianza e marxe de erro

\begin{tabular}{lcccc}
\hline Colectivo & Poboación & Mostra & $\begin{array}{c}\text { Nivel de } \\
\text { confianza }\end{array}$ & $\begin{array}{c}\text { Marxe } \\
\text { de erro }\end{array}$ \\
\hline Alumnado & 676 & 267 & $95,5 \%$ & $4,67 \%$ \\
Titulados/a & 1.510 & 24 & $95,5 \%$ & $19,85 \%$ \\
Profesorado & 90 & 38 & $95,5 \%$ & $12,15 \%$ \\
Empresas & 5.744 & 38 & $95,5 \%$ & $15,85 \%$ \\
\hline
\end{tabular}

\section{Instrumentos e variables obxecto de estudo}

Tódolos cuestionarios empregados foron deseñados especificamente para a investigación, pasando por un dobre proceso de validación: xuízo de expertos e realización de probas piloto. Trala realización destas probas, obtivéronse catro cuestionarios diferenciados compostos por ítems tanto abertos como pechados —dicotómicos, politómicos e de escala tipo Likert—. Na táboa que se presenta a continuación podemos apreciar o número de variables e ítems que compoñen cada un dos cuestionarios, así como o coeficiente de alfa de Cronbach, que determina a fiabilidade do instrumento en cada caso. Dado que todos eles superan o índice 0.7, podemos afirmar que os instrumentos poden ser considerados consistentes e válidos para a obtención de resultados fiables.

Táboa 2.

Número de ítems, variables e coeficiente alfa de Cronbach de cada un dos cuestionarios

\begin{tabular}{lccc}
\hline Cuestionario & $\begin{array}{c}\text { Número } \\
\text { de ítems }\end{array}$ & $\begin{array}{c}\text { Número de } \\
\text { variables }\end{array}$ & $\begin{array}{c}\text { Coeficiente } \boldsymbol{\alpha} \\
\text { de Cronbach }\end{array}$ \\
\hline Alumnado & 40 & 103 & .75 \\
Titulados/as & 45 & 116 & .79 \\
Profesorado & 54 & 129 & .74 \\
Empresas & 39 & 122 & .94 \\
\hline
\end{tabular}

As variables que compoñen cada un dos cuestionarios agrúpanse en tres bloques de contido: datos persoais e contextuais; a relación entre a FP, o emprego e o desenvolvemento humano sustentable no marco local e, por último, currículo e docentes de FP e a súa relación co desenvolvemento. Centrarémonos no segundo dos bloques relativo á análise da relación entre a FP, o emprego e o desenvolvemento humano sustentable no marco local e, máis concretamente, respecto da vinculación entre os centros educativos e, por extensión, o profesorado de FP respecto das organizacións que compoñen a súa contorna máis próxima.

Para finalizar, cabe sinalar que a análise estatística dos datos cuantitativos procedentes dos cuestionarios levouse a cabo baixo a utilización do programa PASW Statistics 18.

\section{Resultados: o capital social ao redor da FP inicial no territorio comarcal}

Tomando en consideración os resultados obtidos dos cuestionarios, pretendemos realizar unha valoración das (inter)conexións existentes entre os distintos axentes sociais que constrúen a FP Inicial no territorio comarcal do Barbanza, así como o grao de Responsabilidade social que declaran as empresas enquisadas.

Segundo a apreciación dos docentes de FP (ver figura 1), os contactos máis frecuentes — case diarios e tamén semanais- do seu centro educativo son coa Administración Educativa Autonómica: un 21\% dos enquisados/as así o sinala no primeiro caso e un $23,7 \%$ no segundo. Ao contrario, para a maior parte dos docentes $(36,8 \%)$ os contactos coas empresas da comarca son mensuais, mentres que co concello se manterían contactos anuais (26,3\%) e non existiría relación algunha coas axencias ou institucións de desenvolvemento comarcais ou locais (26,3\%). 


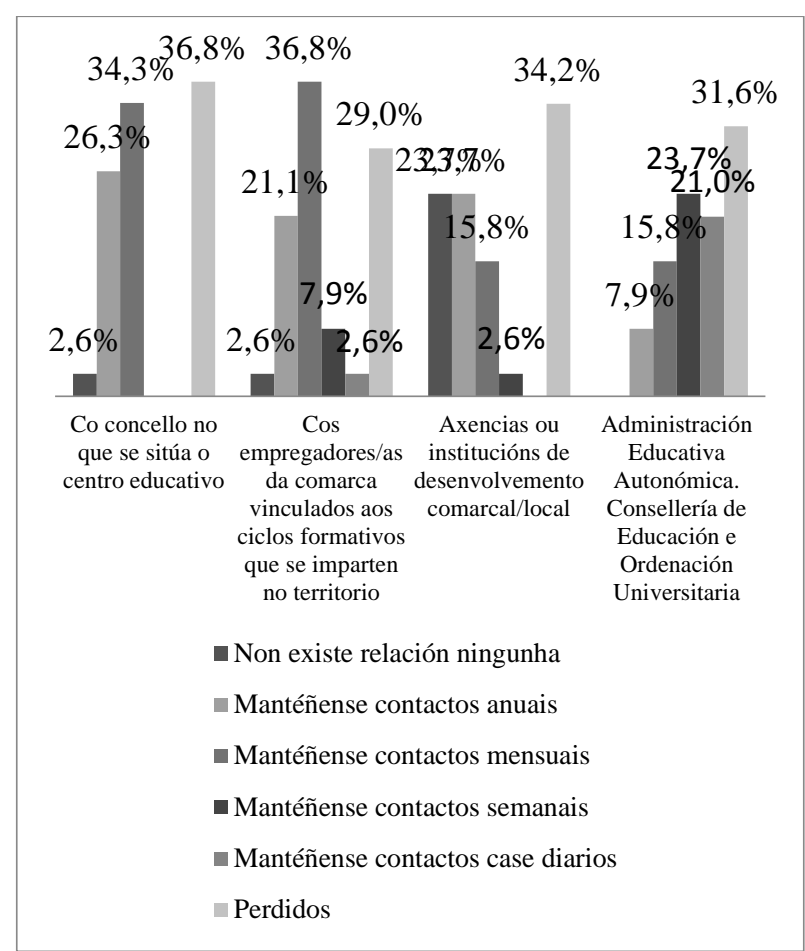

Figura 1. Frecuencia do contacto entre os centros de FP e outros axentes sociais locais e autonómicos

Na táboa 3 podemos apreciar estes datos de forma máis precisa, posto que nela se especifican os axentes sociais máis sinalados polo colectivo de docentes en función da frecuencia do contacto co centro. Neste senso, a Administración Educativa Autonómica ocupa un papel preponderante nas relacións que afirman os profesores/as que manteñen con outras organizacións vinculadas coa FP. Ao mesmo tempo, os empregadores/as vinculados cos ciclos que se imparten no centro educativo son sinalados maioritariamente como contacto mensual (36,8\%), ocupando así unha posición intermedia entre aqueles/as axentes cos que máis cantidade de relación se establece e aqueles/as cos que esta é ínfima ou inexistente -neste caso o concello e as axencias ou institucións de desenvolvemento-.

Táboa 3.

Axentes sociais máis sinalados polo colectivo de docentes en función da frecuencia de contacto que o centro mantén con eles

\begin{tabular}{|c|c|}
\hline \begin{tabular}{|c|}
$\begin{array}{c}\text { Frecuencia do } \\
\text { contacto }\end{array}$ \\
\end{tabular} & Axente Social \\
\hline $\begin{array}{l}\text { Mantéñense contactos } \\
\text { case diarios } \\
\text { Mantéñense contactos } \\
\text { semanais } \\
\text { Mantéñense contactos } \\
\text { mensuais }\end{array}$ & $\begin{array}{l}\text { Administración Educativa } \\
\text { Autonómica (21\%) } \\
\text { Administración Educativa } \\
\text { Autonómica }(23,7 \%) \\
\text { Empregadores/as da comarca } \\
\text { vinculados aos ciclos formativos } \\
\text { que se imparten no territorio } \\
(36,8 \%)\end{array}$ \\
\hline $\begin{array}{l}\text { Mantéñense contactos } \\
\text { anuais } \\
\text { Non existe relación } \\
\text { ningunha }\end{array}$ & $\begin{array}{l}\text { Concello no que se sitúa o centro } \\
\text { educativo ( } 26,3 \%) \\
\text { Axencias ou institucións de } \\
\text { desenvolvemento comarcal/local } \\
(23,7 \%)\end{array}$ \\
\hline
\end{tabular}

Sen embargo, se analizamos a perspectiva maioritaria dos empresarios/as enquisados (ver figura 2), respecto do nivel de relacións que manteñen cos axentes sociais vinculados coa FP, constatamos que un $60,5 \%$ dos mesmos sinala non manter ningún tipo de relación cos centros de FP da comarca.

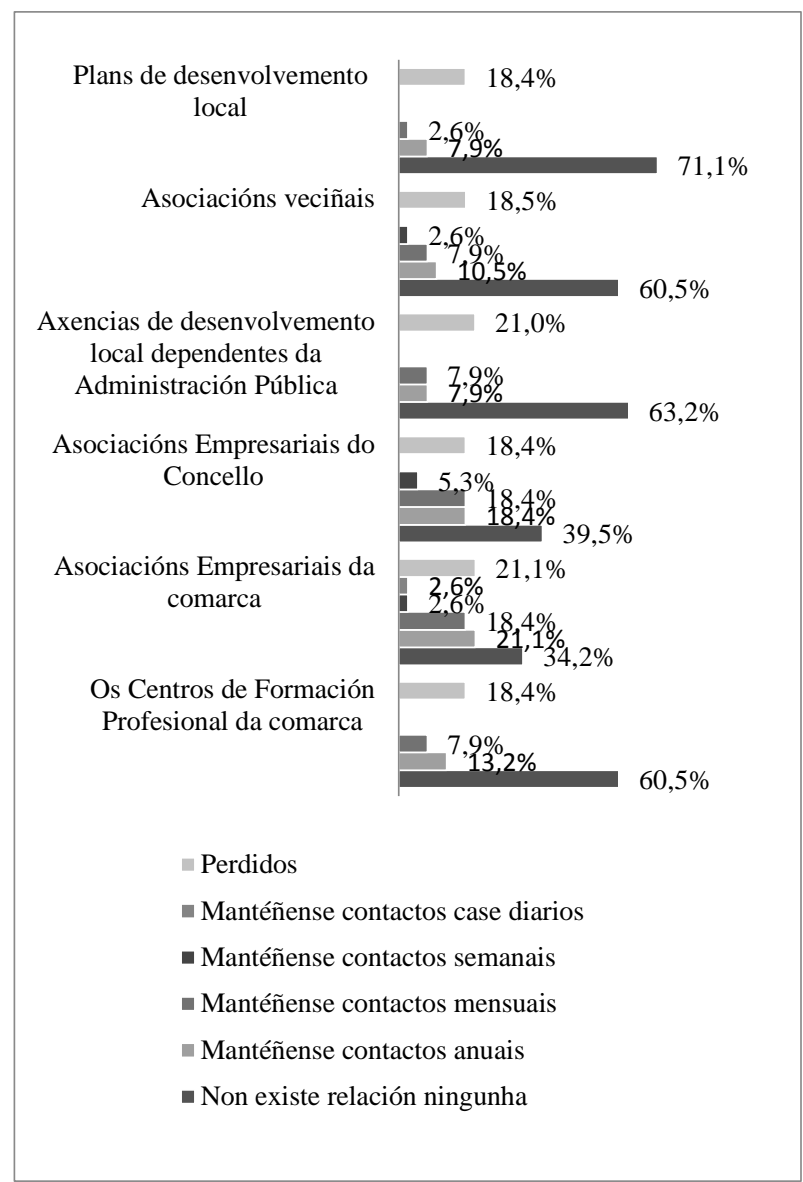

Figura 2. Frecuencia do contacto entre os empresarios/as da comarca e outros axentes sociais vinculados á FP

Isto pode ser debido ao feito de que na súa maioría estes tampouco colaboran na realización do módulo de FCT: un 65,8\% dos enquisados/as está nesta situación, mentres que só un $18,4 \%$ vai afirmar colaborar cos centros educativos no desenvolvemento deste módulo. Aínda así, non deixa de resultar significativo que os centros educativos e as empresas vinculadas aos ciclos formativos que imparten, só manteñan contacto a raíz da organización do módulo de FCT, aspecto que reitera a importancia deste módulo para a superación da fenda entre sistema educativo e produtivo, pero que tamén é insuficiente para asegurar un contacto constante e unha coordinación e colaboración real entre empresas e centros de FP. Nesta mesma dirección se manifestan o $39,4 \%$ dos docentes, o $13,8 \%$ dos empresarios/as e o $11,2 \%$ dos titulados/as cando foron enquisados/as acerca das medidas que proporían para mellorar a inserción laboral dos titulados/as en FP da comarca. De feito, ante esta cuestión algúns dos empresarios/as manifestaron que, entre outras medidas, sería preciso: Antes de nada conocer la oferta de la zona, sólo nos enteramos cuando no tienen dónde colocar a alguien para las prácticas 
(suxeito 7) ou que el centro que imparte los ciclos formativos debería encargarse del contacto con las empresas de la comarca para enviar currículums o para la realización de prácticas remuneradas o no (suxeito 18).

O contacto polo tanto, entre empresas e profesorado ou centros educativos debe aumentar cuantitativamente, aínda que isto non nos pode facer esquecer que a verdadeira importancia do establecemento de redes de traballo (networking) e a xeración de capital social, vai vir determinado non só polo número de contactos que se establecen, senón tamén pola calidade dos mesmos de cara ao fornecemento dunha colaboración real, a cal se deberá ver traducida nunha maior - e mellorinserción profesional dos titulados/as en na propia comarca. Para isto, é de vital importancia contar cunha perspectiva global de actuación, planificada e aplicada en base a uns obxectivos comúns de desenvolvemento do territorio, os cales deben vir establecidos a nivel da administración pública -lembremos que segundo Woolcock e Narayan (2000) o papel do estado en canto a facilitar resultados positivos de desenvolvemento é o máis importante (e tamén o máis problemático)—, debendo actuar este como coordinador xeral dos pasos dados en cada unha das institucións e organismos que compoñen o territorio. Neste senso, o papel xogado polas Administracións públicas debería, baixo o noso punto de vista, verse materializado na labor desempeñada polas denominadas Axencias de desenvolvemento comarcal/local, así como polo propio concello. Se analizamos as relacións que tanto centros educativos como entidades empresariais afirman manter con cada un deles, podemos apreciar como os contactos - de existiren- caracterízanse por ser maioritariamente de carácter anual. O axente máis sinalado nesta categoría de contactos anuais polos docentes é o concello (26,3\%) (ver táboa 3), o cal non resta que, tomando o concello como referencia, a maior parte dos docentes (34,3\%) sinale que se manteñen contactos mensuais (ver figura 1). Respecto dos empresarios/as, as institucións coas que máis relacións teñen son as asociacións patronais, ben da comarca, ben do concello. Todas elas aparecen como a opción máis sinalada respecto do axente social co que máis contacto se ten a nivel diario, semanal, mensual e anual (ver táboa 4).

Táboa 4.

Axentes sociais máis sinalados polo colectivo de empresarios/as en función da frecuencia de contacto que o centro mantén con eles

\begin{tabular}{ll}
\hline \multicolumn{1}{c}{$\begin{array}{c}\text { Frecuencia do } \\
\text { contacto }\end{array}$} & \multicolumn{1}{c}{ Axente Social } \\
\hline $\begin{array}{l}\text { Mantéñense contactos } \\
\text { case diarios }\end{array}$ & $\begin{array}{l}\text { Asociacións empresariais da } \\
\text { comarca (2,6\%) }\end{array}$ \\
Mantéñense contactos & $\begin{array}{l}\text { Asociacións empresariais do } \\
\text { concello (5,3\%) }\end{array}$ \\
semanais & Asociacións empresariais da \\
Mantéñense contactos & comarca (18,4\%) \\
mensuais & $\begin{array}{l}\text { Asociacións empresariais do } \\
\text { concello (18,4\%) }\end{array}$ \\
Mantéñense contactos & $\begin{array}{l}\text { Asociacións empresariais da } \\
\text { comarca (21,1\%) }\end{array}$ \\
anuais &
\end{tabular}

\begin{tabular}{ll}
\hline \multicolumn{1}{c}{$\begin{array}{c}\text { Frecuencia do } \\
\text { contacto }\end{array}$} & \multicolumn{1}{c}{ Axente Social } \\
\hline $\begin{array}{l}\text { Non existe relación } \\
\text { ningunha }\end{array}$ & $\begin{array}{l}\text { Plans de desenvolvemento local } \\
(71,1 \%)\end{array}$ \\
\hline
\end{tabular}

Neste senso, os empresarios/as sinalan maioritariamente non manter relación ningunha cunha grande parte dos axentes sociais mencionados (ver figura 2): o 71,1\% non mantén contacto ou colaboración con ningún Plan de desenvolvemento local; o 60,5\% non mantén relación coas asociacións veciñais; o 63,2\% non mantén contacto coas axencias ou institucións de desenvolvemento e o 60,5\% non mantén ningún tipo de relación cos centros de FP do territorio, tal e como vimos de sinalar. Na liña do anterior, tamén é preciso destacar que non existe colaboración de ningún tipo por parte da maioría das empresas para con ningún Plan de desenvolvemento local, o cal pon de manifesto a pasividade das administracións locais e da sociedade en xeral respecto a este tema. De igual modo, esta ausencia de contacto entre as empresas e outros axentes sociais -máis alá de provedores ou clientes-, sinala que dalgunha maneira, cada organización leva a cabo a súa actividade económica sen establecer pontes de colaboración coas administracións públicas respecto daqueles temas que lles afectan e dos que forman parte activamente, neste caso a o emprego e por extensión a FP. Algo similar lles ocorre aos propios centros de FP, aínda que en menor medida: a pesar de que os contactos establecidos non son os que de forma óptima poderíamos desexar para lograr unha conexión real entre o sistema educativo e o laboral, é certo que existen máis pontes entre ditos centros e outras institucións sociais do que ocorre coas empresas. De feito, algúns dos docentes incluso destacan que o seu centro colabora con Confrarías de Pescadores; Axencias de desenvolvemento do concello; o Servizo Galego de Colocación ou as Confederacións de Empresarios/as (ver táboa 5).

Táboa 5.

Respostas dos docentes á cuestión de con que institucións/axencias de desenvolvemento comarcal/local manteñen contacto

\begin{tabular}{cl}
\hline Suxeito & \multicolumn{1}{c}{ Resposta } \\
\hline 6 & -Confrarías Pescadores \\
7 & - Empresas de pesca para FCT \\
9 & $\begin{array}{l}\text { - Axencia de desenvolvemento local do } \\
\text { concello. }\end{array}$ \\
& - Desenvolvemento comarcal Ribeira \\
33 & $\begin{array}{l}\text { - Servizo galego de colocación, oficina pública } \\
\text { de emprego. } \\
\text { - Confederación empresarios. }\end{array}$ \\
\end{tabular}

\section{Conclusións}

A teoría do capital social é un elemento clave dentro da perspectiva endóxena representada polo modelo do desenvolvemento humano sustentable, polo que a influencia do mesmo nas contornas locais en relación á FP representa un dos retos aos que se enfrontan as organizacións públicas e privadas. A incorporación do capital social como política de desenvolvemento implica, 
entre outras premisas e segundo Woolcock e Narayan (2000), a necesidade de facer máis transparentes os servizos e institucións, tanto públicas como privadas, así como levar a cabo as intervencións de cara ao desenvolvemento dende a perspectiva do capital social, avaliando ao mesmo tempo o seu impacto e tendo en conta que as redes internas das comunidades empobrecidas representan parte da súa identidade, polo que é preciso non tentar eliminalas, senón establecer vías alternativas que os relacionen con outros grupos.

Baixo estes elementos, a planificación da oferta formativa de acordo coas achegas dos axentes sociais e tomando como criterio básico a correspondencia entre o tipo de FP a instaurar nunha rexión e as necesidades de cualificación da mesma, constitúese como un axente dinamizador e promotor da cohesión social xeral (Blas Aritio, 2010). Tal como xa sinalamos noutra ocasión (Rego Agraso, Rial Sánchez e Barreira Cerqueiras, 2015), baixo unha planificación caracterizada por estes dous criterios básicos, a efectividade da FP en relación coa inserción, previsiblemente sería moito maior, polo que actuaría como política activa de emprego e promovería en ultima instancia, a cohesión social. Medidas como esta, combinadas con elementos como a prevención e redución do fracaso escolar; unha axeitada preparación para a inserción laboral ou o establecemento de conexións entre a FP regrada e outras etapas do sistema educativo, así como co subsistema de FP para o emprego, supoñen accións que favorecen a aparición de capital social vinculado con estas ensinanzas, polo que é preciso incidir dende as Administracións públicas na súa consecución.

De igual modo, para acadar maiores cotas de capital social a nivel comunitario e tamén dentro do propio marco da FP, é preciso mellorar os niveis de confianza establecidos entre os diferentes axentes sociais participantes, neste caso, no proceso formativo -alumnado-profesorado; alumnado-empresas e profesorado-empresas-, para o que resulta de vital importancia establecer obxectivos comúns a tódolos axentes, como por exemplo a dotación de recursos humanos para as empresas do territorio ou a eliminación das desigualdades de xénero nas profesións masculinizadas (Mariño Fernández, 2008). Neste senso, a persistencia dunha barreira infranqueable entre a FP regrada e a FP para o emprego debe ser superada, desenvolvendo unha cultura da aprendizaxe permanente e establecendo vínculos máis estreitos entre ambas modalidades formativas, ata chegar a construír un Sistema de Cualificacións plenamente transparente e integrado, onde sexa posible pasar dunhas modalidades a outras de forma accesible, así como recoñecer aquelas aprendizaxes adquiridas pola vía da experiencia profesional dunha forma moito máis áxil e factible para os interesados/as.

De igual xeito, semella imprescindible superar a barreira física entre o centro educativo e a empresa. Ambas organizacións deben traballar de forma conxunta para favorecer a cualificación da poboación, establecendo vínculos estables e dinámicos que se reflictan nun seguimento o máis individualizado posible do proceso formativo e de inserción do alumnado. Outras iniciativas neste senso teñen que ver co incremento das cifras de acollementos do profesorado nas empresas, así como de empresarios/as que coñezan o funcionamento real dos centros educativos e o que se espera deles como titores do Módulo de Formación en Centros de Traballo.

É cada vez máis relevante nun mundo interconectado, superar o illamento dos centros respecto da súa contorna inmediata, especialmente a que configura o seu mercado laboral directo, así como daquelas profesións con tradición histórica nese contexto. O alumnado dunha determinada zona debe ser quen de coñecer os sectores produtivos que xeran emprego no seu territorio, así como as súas posibilidades reais de inserción laboral no mesmo e as vinculacións coa economía tradicional da zona.

En conclusión, para crear e xestionar adecuadamente o capital social nas organizacións educativas, inicialmente é preciso decatarse e asumir a súa presenza, así como as posibilidades de influenza que este ten no devir persoal e colectivo dos individuos que compoñen unha comunidade e na súa inserción laboral.

\section{Referencias}

Atria, R. (2003). Capital social: concepto, dimensiones y estrategias para su desarrollo. En R. Atria e M. Siles (Comp.). Capital social y reducción de la pobreza en América Latina y el Caribe: en busca de un nuevo paradigma (581-590). Santiago de Chile: CEPAL/Michigan State Univesity.

Blas Aritio, F. (2010b). La Formación Profesional para la cohesión social. El caso de España. En C. Jacinto (Coord.) (2010). Formación Profesional y cohesión social. Madrid: Fundación Carolina CeAlci.

Fukuyama, F. (2003). Capital Social y Desarrollo: la agenda venidera. En R. Atria e M. Siles (Comp.) Capital Social y reducción de la pobreza en América Latina y El Caribe: En busca de un nuevo paradigma (33-48). Santiago de Chile: CEPAL/Michigan State University.

Mariño Fernández, R. (2008). Análisis de la trayectoria formativa de la mujer en las ramas industriales de F.P. en Galicia y su inserción socio-laboral. Tesis doctoral.. Dpto. Didáctica e Organización Escolar, Universidade de Santiago de Compostela, Santiago de Compostela, España.

Rego Agraso, L. (2013). A ordenación da Formación Profesional inicial $e$ a súa vinculación co desenvolvemento socioeconómico dos territorios comarcais galegos. Tese de doutoramento. Dpto. Didáctica e Organización Escolar, Universidade de Santiago de Compostela, Santiago de Compostela, España.

Rego Agraso, L., Rial Sánchez, A. e Barreira Cerqueiras, E.M. (2015). La formación en alternancia en la universidad y en los ciclos formativos: aportaciones desde dos investigaciones realizadas en Galicia. Revista Educar, Vol. 51, $N^{\circ}$ 2, 349-371.

Woolcock, M. e Narayan, D. (2000). Social capital: implications for development theory, research and policy. The world bank research observer, 15 (2), 225-249. 